\title{
CORRESPONDENCE
}

\section{Pulmonary tuberculosis in the differential diagnosis of community-acquired pneumonia}

\section{To the Editors:}

Especially in view of the need to maintain a high index of suspicion for tuberculosis (TB) in elderly patients and in patients with HIV infection, I would like to add to the reservations expressed about the guidelines for the management of adults lower respiratory tract infections [1, 2] by voicing concern about another aspect of the guidelines. In this instance, I would like to draw attention to the omission of any mention of the role of Mycobacterium tuberculosis either as an alternative aetiology for radiographic and clinical stigmata simulating community-acquired pneumonia (CAP) $[3,4]$ or as a co-pathogen even when Streptococcus pneumoniae is the acknowledged bacterial aetiological agent $[5,6]$.

In the former context, "failure to respond to antimicrobial agents for common bacterial pneumonias should prompt concern that TB is a possible cause", as was the case in a 25yr-old febrile patient who was referred for presumed pneumonia unresponsive to antibiotics, and in whom pulmonary $\mathrm{TB}$ proved to be the underlying cause of right lower lobe consolidation [3]. A high index of suspicion for M. tuberculosis as an alternative diagnosis should also prevail in the elderly [4], given the fact that there is an age-related increase in the prevalence of M. tuberculosis-related lower-lobe disease, and in view of the fact that "frequency of cavitation in the TB group showed a negative correlation with age" in a study by PEREZGUZMAN et al. [4]. The role of M. tuberculosis as a co-pathogen was exemplified by 11 patients belonging to a subgroup of 222 with CAP characterised by typical respiratory symptoms and positive chest radiography associated with an identifiable respiratory pathogen. In those 11 patients, S. pneumoniae CAP coexisted with sputum-positive pulmonary TB [5]. In yet another study, nine patients were reported with bacteraemic S. pneumoniae CAP and concomitant pulmonary TB. These patients were admitted with brief history of respiratory symptoms and fever, and none was previously diagnosed with HIV infection. Chest radiographs all showed lobar or multilobar consolidation, and blood cultures were positive for S. pneumoniae. Although symptoms and pyrexia initially abated after antibiotics, all nine patients subsequently experienced recurrence of symptoms and pyrexia associated with non-resolution of radiographic stigmata. Co-existing $M$. tuberculosis was subsequently diagnosed by sputum smear in five instances, by mycobacterial culture of bronchial washings in two patients, by mycobacterial culture of a transbronchial specimen in one patient and, in one case, by mycobacterial blood culture. All nine patients also subsequently tested positive for HIV infection [6]. In view of these examples, TB should also feature in the differential diagnosis of unresolved pneumonia, and guidelines should, arguably, also specify which patients should have post-discharge clinical and radiological review.

These reservations aside, the guidelines are well researched and well balanced. Above all, they reinforce good practice by stressing the primacy of identifying the culprit pathogen so that antibiotic therapy can be more targeted, thereby mitigating the risk of side-effects from inappropriate medication with broad-spectrum antibiotics.

\section{Oscar M.P. Jolobe}

Manchester Medical Society, c/o John Rylands University Library, Oxford Road, Manchester, UK.

Correspondence: O.M.P. Jolobe, 1 Philip Godlee Lodge, 842 Wilmslow Road, Manchester, M20 2DS, UK. E-mail: oscarjolobe@ yahoo.co.uk

Statement of Interest: None declared.

\section{REFERENCES}

1 Woodhead M. New guidelines for the management of adult lower respiratory tract infections. Eur Respir J 2011; 38: 1250-1251.

2 Woodhead M, Blasi F, Ewig S, et al. Guidelines for the management of adult lower respiratory tract infections. Clin Microbiol Infect 2011; 17: Suppl. 6, E1-E59.

3 Buckner CB, Leithiser RE, Walker CW, et al. The changing epidemiology of tuberculosis and other mycobacterial infections in the United States: implications for the radiologist. AJR Am J Roentgenol 1991; 156: 255-264.

4 Perez-Guzman C, Torres-Cruz A, Villarreal-Velarde $\mathrm{H}$, et al. Progressive age-related changes in pulmonary tuberculosis images and the effect of diabetes. Am J Respir Crit Care Med 2000; 162: 1738-1740.

5 Nyamande K, Lallo UG, John M. TB presenting as communityacquired pneumonia in a setting of high TB incidence and high HIV prevalence. Int J Tuberc Lung Dis 2007; 11: 1308-1313.

6 Schleicher GK, Feldman C. Dual infection with Streptococcus pneumoniae and Mycobacterium tuberculosis in HIV-seropositive patients with community-acquired pneumonia. Int J Tuberc Lung Dis 2003; 7: 1207-1208.

DOI: 10.1183/09031936.00004312 